\title{
A Study of Radiation Doses to the Patient and Medical Team at Embolization Procedures
}

\author{
Alvaro Vilas Boas Castilho*, Denis Szjenfeld, Darcio Nalli, Vinicius Fornazari, Antonio Carlos Moreira, \\ Regina Bitelli Medeiros \\ Departamento de Diagnóstico por Imagem, Federal University of São Paulo, UNIFESP, Rua Vieira de Moura, Vila Mariana-SP, Brazil
}

\section{Original Research}

Received January 21, 2019

Revision March 20, 2019

Accepted April 3, 2019

Corresponding author:

Alvaro Vilas Boas Castilho

Departamento de Diagnóstico por Imagem, Federal University of São Paulo, UNIFESP CEP: 04117-150, Rua Vieira de Moura, 48 Vila Mariana -SP, Brazil

Tel: +5511970292829

E-mail: alvaro_vilasboas@hotmail.com

This is an Open-Access article distributed under the terms of the Creative Commons Attribution NonCommercial License (http://creativecommons.org/ licenses/by-nc/4.0) which permits unrestricted noncommercial use, distribution, and reproduction in any medium, provided the original work is properly cited.

Copyright $\odot$ 2019The Korean Association for Radiation Protection

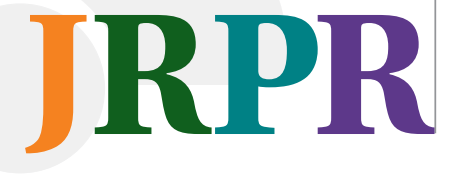

Background: This study aimed to estimate occupational doses and patient peak skin doses (PSDs) during interventional radiology procedures.

Materials and Methods: We examined data from brain embolization $(n=30)$, hepatic chemoembolization $(n=50)$, and uterine embolization $(n=12)$. The PSDs were measured using radiochromic film around the patient's head (group 1) or abdominal/pelvic region (group 2). Acquisition technical data and kerma-area products (KAP) were also recorded. Occupational doses were measured using Instadose ${ }^{\mathrm{TM}}$ dosimeters near the left eye region (LER), chest, and left ankle.

Results and Discussion: The third quartile (median) KAP values were $408.1(235.3) \mathrm{Gy} \cdot \mathrm{cm}^{2}$ for group 1 and $584.4(449.4) \mathrm{Gy} \cdot \mathrm{cm}^{2}$ for group 2. The average PSDs were greatest during vascular procedures, reaching 1,004.4 (786.4) $\mathrm{mGy}$, and the highest PSD was 2,352.6 mGy (during hepatic chemoembolization). The third quartile (median) occupational doses were 0.35 $(0.21) \mathrm{mSv}$ at the LER, $0.25(0.15) \mathrm{mSv}$ at the chest, and $1.47(0.64) \mathrm{mSv}$ at the left ankle. Occupational doses at the LER were higher than at the chest, which highlights the importance of protective glasses and suspended shields. The occupational doses at the ankle region were also high, which highlights the importance of using a lead-lined curtain attached to the table.

Conclusion: The results indicate that physicians can reach, for eye region, the weekly occupational dose limit after around 15 procedures, even when using proper protection. The average PSD values were below the threshold for tissue reactions, although the complexity of these procedures emphasises the importance of considering related risks.

Keywords: Embolization, Peak Skin Dose, Occupational Dose, Interventional Radiology

\section{Introduction}

Interventional radiology guided by fluoroscopy can facilitate the diagnosis and treatment of numerous diseases, and has reduced the risk of patient death [1, 2]. These procedures are considered minimally invasive and provide good therapeutic efficacy [2-4]. However, during these procedures, the patient and medical team receive high radiation doses, which highlights the importance of optimizing radiation protection $[2,5,6]$. For example, during embolization procedures, some patients may receive doses that exceed the threshold for tissue reactions [7, 8]. Furthermore, treatment complexity and the patient's clinical condition can increase the risk to both the patient and the medical team $[9,10]$. Therefore, dosimetry evaluations are essential for estimating doses and optimizing the protection of the patient and medical team [7]. 
Various studies have examined the radiation dose that is absorbed by the patient's skin [11, 12]. In addition, studies have revealed large variations in the radiation dose during cerebral embolization, both at the same hospital and at different hospitals, which most commonly lead to alopecia [3, 11, 13-16]. Thus, the International Atomic Energy Agency (IAEA) recommends that the patient's peak skin dose (PSD) should be kept below $2 \mathrm{~Gy}$, in order to avoid tissue reactions that include alopecia, erythema, and necrosis $[17,18]$.

Various organizations have also alerted medical professionals to the risks of radiation exposure, such as the International Commission on Radiological Protection, the United Nations Scientific Committee on the Effects of Atomic Radiation, the IAEA, and the National Council on Radiation Protection. Furthermore, the National Council on Radiation Protection has described various technical parameters to evaluate radiation dose, such as the kerma-area product (KAP), cumulative kerma, and total exposure time. The data from these parameters can be useful for routine monitoring and to indicate the need for clinical follow-up in order to monitoring skin injuries or tissue reactions $[19,20]$. Moreover, the United Nations Scientific Committee on the Effects Atomic Radiation has reported that interventional procedures are associated with the greatest occupational exposure [21]. Therefore, three IAEA projects (ORAMED, 2008-2011; ELDO, 2013; and EURALOC, 2014-2017) have been performed to develop protection measures for use during interventional radiology.

Studies of occupational exposure have revealed that prolonged radiation exposure during fluoroscopy-guiding interventional procedures can lead to severe ocular damage [10]. In addition, Vaño et al. [22] reported that physicians and medical team members experienced early radiation-induced changes in the eye lens, which emphasizes the urgent need for improvements in radioprotection, professional training, eye protection using during catheterisation, and oc- cupational dosimetry improvement. Vaño et al. [22] have also suggested that a dosimeter at the C-arm's isocentre should be used as a reference to estimate scattered radiation doses near the patient, and that the dosimeter could be used to conservatively estimate occupational doses to the eyes when a personal dosimeter is not used for any reason [23]. Roguin et al. [24] also reported 31 cases of head and neck cancer in healthcare professionals who were occupationally exposed to radiation during cardiac and interventional procedures. Finally, fluoroscopy-guided interventional procedures may be associated with eye lens damage and tumours over time among physicians and medical team members [2, $9,10,22,25,26]$. Therefore, the present study aimed to determine occupational doses and patient PSDs in cases of neuroembolization, hepatic artery chemoembolization, and uterine artery embolization.

\section{Materials and Methods}

The study's protocol was approved by the ethics committee of São Paulo Federal University (187 614). Data collection during the interventional therapeutic procedure occurred between 2013 and 2016, but the clinical follow-up considering skin disease was performed until 2018.

We evaluated 92 therapeutic embolization procedures that were performed at our centre using a Philips Integris Allura V5000, Massachusetts, USA, digital system with an image intensifier and a $25-38 \mathrm{~cm}$ field of view (FOV). The patients were divided according to whether they underwent neuroembolisation (group 1) or vascular embolisation (group 2). Group 1 included patients (men and women who were 1572 years old) with vascular disease in their neurological system, such as aneurysm $(n=20)$ or arteriovenous malformation ( $\mathrm{n}=10)$. Group 2 included 50 patients who underwent chemoembolization for hepatic neoplasms (men and women who were 19-75 years old) and 12 women with uterine

Table 1. Embolization Protocols used in Procedures into Groups 1 and 2

\begin{tabular}{|c|c|c|c|c|c|c|c|c|c|c|c|}
\hline \multicolumn{4}{|c|}{ Group 1} & \multicolumn{8}{|c|}{ Group 2} \\
\hline \multicolumn{4}{|c|}{ Aneurism/AVM } & \multicolumn{4}{|c|}{ Hepatic Chemoembolization } & \multicolumn{4}{|c|}{ Myoma Chemoembolization } \\
\hline \multicolumn{4}{|c|}{ Total Images: 55} & \multicolumn{4}{|c|}{ Total Images: 70} & \multicolumn{4}{|c|}{ Total Images: 33} \\
\hline Protocol & Run & Time (sec) & Frames/s & Protocol & Run & Time (sec) & Frames/s & Protocol & Run & Time (sec) & Frames/s \\
\hline \multirow[t]{3}{*}{ Cerebral } & 1 & 10 & 3 & Abdomen & 1 & 20 & 2 & Pelvis & 1 & 6 & 3 \\
\hline & & 10 & 2 & & & 20 & 1 & & & 5 & 2 \\
\hline & & 5 & 1 & & & 2 & 0.5 & & & 10 & 0.5 \\
\hline
\end{tabular}

Font: Philips Allura V5000. 
myoma (29-41 years old). The monitoring data included fluoroscopy time, number of images, KAP $\left(\mathrm{Gy} \cdot \mathrm{cm}^{2}\right)$, voltage $(\mathrm{kVp})$, electric current $(\mathrm{mA})$, and FOV. Table 1 shows the protocols that were routinely used during the therapeutic procedures.

The occupational doses to the physicians and nurses (personal dose equivalent) were evaluated using direct-read Instadose $^{\mathrm{TM}}$ dosimeters, Mirion Technologies Dosimetry, California, USA. These dosimeters use proprietary direct ion storage technology, and are accredited in the USA through the National Voluntary Laboratory Accreditation Program (NVLAP code: 100555-0). The Instadose ${ }^{\mathrm{TM}}$ dosimeters were placed at the sphenoidal region (near the eyes), over the apron at the chest level, and at the left ankle. A suspended ceiling and lateral curtain were rarely used during the procedures. The nurses wore anterior and posterior dosimeters over the apron at the chest level. Only the physicians wore lead glasses with lateral protection, though they did not use special gloves as radioprotection tool for their hands. Similar to a previous study, we used an Instadose ${ }^{\mathrm{TM}}$ device at the Carm isocentre as a reference point [22].

A recent study with Instadose ${ }^{\mathrm{TM}}$ dosimeters showed a satisfactory response face on main dosimetric properties and also clinical conditions encountered in interventional radiology and cardiology [28].

The peak skin doses (PSD) were measured using Gafchromic XR-RV3 film, Ashland Advanced - New Jersey, USA (dose range: 0.01-30 Gy; energy range: $30 \mathrm{keV}$ to $30 \mathrm{MeV}$; size: 14 " $\times 7$ "), which had been calibrated at $80 \mathrm{kVp}$ for the half value layer (HVL) equal to $3.2 \mathrm{~mm} \mathrm{Al}$. It was used in the Philips X-ray equipment, Compact Plus $500 \mathrm{VMI}$ model, and the dose range was from 10 to $800 \mathrm{cGy}$. The optical readings were performed using a PEHAMED Densoquick2, densitometer (Taunus -Deutschland). All blackened regions were selected on each film, and at least three readings were taken at each region in order to determine the maximum optical density.

Twelve patients at group 1 had worn a radiotransparent cranial support that was internally coated with radiochromic film. Sixteen patients at Group 2 underwent hepatic chemoembolization procedures and had the films positioned under their abdominal region.

\section{Results}

The tube potential and current were adjusted according to the patient's thickness using automatic exposure control, with ranges of 77-82 kV and 1.5-3.9 mA in group 1 and 80$110 \mathrm{kV}$ and 1.8-8.4 $\mathrm{mA}$ in group 2. The FOV sizes were $25 \mathrm{~cm}$ and $31 \mathrm{~cm}$ in group 1, compared to $25 \mathrm{~cm}, 31 \mathrm{~cm}$, and $38 \mathrm{~cm}$ in group 2.

Tables 2, 3 provide the doses from the angiographic equipment's display at the end of the procedure, as well as the technical parameters from during the therapeutic proce-

Table 2. Kerma Air Area Product (KAP) Values Obtained at Embolization Procedures

\begin{tabular}{|c|c|c|c|c|c|c|c|c|c|}
\hline \multirow{3}{*}{$\begin{array}{l}\text { Procedures } \\
\text { Measures }\end{array}$} & \multirow{2}{*}{\multicolumn{3}{|c|}{$\begin{array}{c}\text { Group } 1 \\
\text { Cerebral (Aneurysm/AVM) } n=30\end{array}$}} & \multicolumn{6}{|c|}{ Group 2 Chemoembolization } \\
\hline & & & & \multicolumn{3}{|c|}{ Hepatic $n=50$} & \multicolumn{3}{|c|}{ Myoma $n=12$} \\
\hline & Mean \pm SD & *75th & Median & Mean \pm SD & *75th & Median & Mean $\pm S D$ & *75th & Median \\
\hline KAP FLUORO (Gy· $\left.\mathrm{cm}^{2}\right)$ & $57.4 \pm 37.3$ & 87.9 & 46.8 & $135.5 \pm 100.9$ & 146.4 & 116.9 & $184.6 \pm 81.0$ & 222.4 & 202.2 \\
\hline KAP CINE $\left(\mathrm{Gy} \cdot \mathrm{cm}^{2}\right)$ & $232.5 \pm 180.1$ & 334.3 & 181.7 & $342.8 \pm 246.6$ & 401.7 & 262.5 & $266.4 \pm 135.6$ & 364.8 & 265.8 \\
\hline KAP TOTAL (Gy $\left.\cdot \mathrm{cm}^{2}\right)$ & $292.5 \pm 200.2$ & 408.1 & 235.3 & $478.3 \pm 320.6$ & 550.8 & 364.8 & $451.0 \pm 197.2$ & 584.4 & 449.4 \\
\hline
\end{tabular}

*75th Percentile Value.

SD, Standard deviation.

Table 3. Technical Operational Conditions Used at Embolization Procedures

\begin{tabular}{|c|c|c|c|c|c|c|c|c|c|}
\hline \multirow{3}{*}{$\begin{array}{l}\text { Procedures } \\
\text { Measures }\end{array}$} & \multirow{2}{*}{\multicolumn{3}{|c|}{$\begin{array}{c}\text { Group } 1 \\
\text { Cerebral (Aneurysm/AVM) } n=30\end{array}$}} & \multicolumn{6}{|c|}{ Group 2 Chemoembolization } \\
\hline & & & & \multicolumn{3}{|c|}{ Hepatic $n=50$} & \multicolumn{3}{|c|}{ Myoma $n=12$} \\
\hline & Mean \pm SD & *75th & Median & Mean \pm SD & *75th & Median & Mean $\pm S D$ & *75th & Median \\
\hline Exposure time (min) & $29.6 \pm 10.9$ & 36.1 & 24.8 & $20.2 \pm 8.5$ & 26 & 18.7 & $31.6 \pm 9.8$ & 34.5 & 32.5 \\
\hline Number of acquisition (Run) & $29.9 \pm 17.4$ & 39.3 & 25.5 & $11.2 \pm 3.7$ & 13 & 11 & $9.6 \pm 17$ & 10.5 & 10 \\
\hline Number of images & $414.2 \pm 254.8$ & 504.5 & 340.5 & $190.1 \pm 64.7$ & 205 & 186 & $152.7 \pm 45.0$ & 189 & 149.5 \\
\hline
\end{tabular}

*75th Percentile Value.

SD, Standard deviation 
Table 4. Occupational and Reference Doses (mSv) Obtained at C-arm Using the Instadose ${ }^{\mathrm{TM}}$ Dosimeter

\begin{tabular}{|c|c|c|c|c|c|c|c|c|c|}
\hline \multirow[b]{3}{*}{ Occupational Dose (mSv) } & \multirow{2}{*}{\multicolumn{3}{|c|}{$\begin{array}{c}\text { Group 1 } \\
\text { Cerebral (Aneurysm/AVM) } n=16\end{array}$}} & \multicolumn{6}{|c|}{ Group 2 Chemoembolization } \\
\hline & & & & \multicolumn{3}{|c|}{ Hepatic $n=36$} & \multicolumn{3}{|c|}{ Myoma n=09 } \\
\hline & Mean \pm SD & *75th & Median & Mean \pm SD & *75th & Median & Mean \pm SD & *75th & Median \\
\hline C-arm (Reference) & $0.63 \pm 0.44$ & 1.16 & 0.37 & $0.52 \pm 0.28$ & 0.62 & 0.46 & $0.84 \pm 0.39$ & 1.06 & 0.89 \\
\hline Physician (left orbit) & $0.11 \pm 0.10$ & 0.21 & 0.11 & $0.27 \pm 0.17$ & 0.37 & 0.25 & $0.27 \pm 0.19$ & 0.31 & 0.20 \\
\hline Physician (anterior thorax) & $0.05 \pm 0.04$ & 0.07 & 0.06 & $0.19 \pm 0.11$ & 0.26 & 0.18 & $0.27 \pm 0.16$ & 0.29 & 0.27 \\
\hline Physician (left ankle) & $0.28 \pm 0.25$ & 0.46 & 0.22 & $1.25 \pm 1.40$ & 1.52 & 0.67 & $1.45 \pm 0.67$ & 2.01 & 1.49 \\
\hline Nursing (anterior thorax) & $0.05 \pm 0.05$ & 0.06 & 0.05 & $0.05 \pm 0.04$ & 0.06 & 0.05 & $0.05 \pm 0.06$ & 0.09 & 0.04 \\
\hline Nursing (posterior thorax) & $0.01 \pm 0.02$ & 0.00 & 0.00 & $0.02 \pm 0.04$ & 0.01 & 0.00 & $0.03 \pm 0.05$ & 0.01 & 0.00 \\
\hline
\end{tabular}

*75th Percentile Value.

SD, Standard deviation.

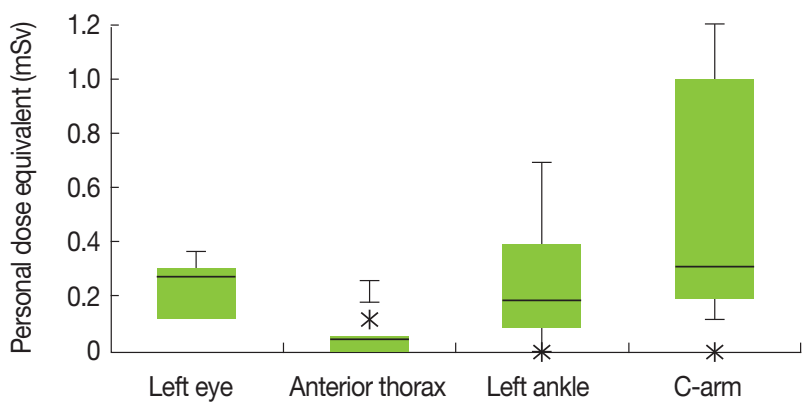

Fig. 1. Occupational Doses during the Therapeutic Procedures at Group 1.

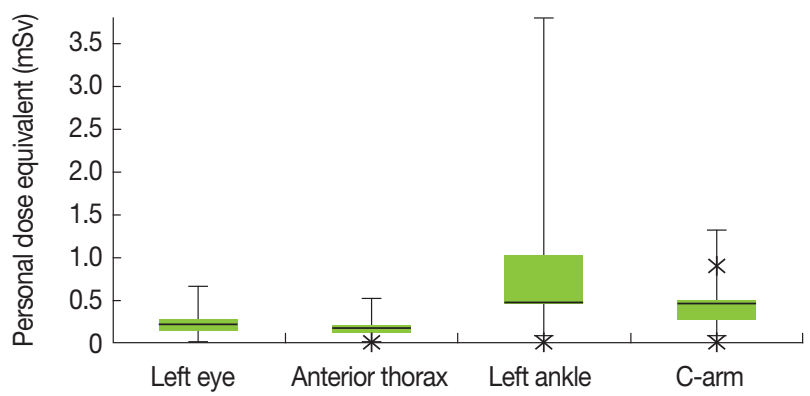

Fig. 2. Occupational Doses during the Therapeutic Procedures at Group 2.

dures. Table 2 shows the fluoro, cine, and total KAP values, while Table 3 shows the values for exposure time, acquisitions, and images.

Table 4 shows the occupational doses at the left orbit, anterior/posterior thorax, and ankle, as well as the reference Carm dose.

Figures 1 and 2 show the personal equivalent doses received during the therapeutic procedures in group 1 and group 2 , respectively.

Table 5 shows the relationship between the physicians' occupational doses and the reference C-arm doses for all procedures.
Table 5. Relation Between Occupational Doses Obtained on Physician's Orbit, Thorax and Ankle and Reference Doses Evaluated at C-arm Using Instadose ${ }^{\mathrm{TM}}$ Dosimeter

\begin{tabular}{lccc}
\hline $\mathrm{n}=57$ & C-arm/orbit & C-arm/thorax & C-arm/Ankle \\
\hline Mean & 0.40 & 0.31 & 1.65 \\
Median & 0.40 & 0.28 & 1.22 \\
3rd Quartile & 0.65 & 0.47 & 2.14 \\
\hline
\end{tabular}

Table 6. Data Collected from Radiochromic Film at Neuroembolization and Hepatic Chemoembolization Procedures

\begin{tabular}{|c|c|c|c|c|c|}
\hline \multicolumn{6}{|c|}{ Maximum Doses on the Patient's Skin (mGy) } \\
\hline Radiochromic film & $n$ & Mean \pm SD & ${ }^{*} 75$ th & Median & Min/Max \\
\hline Group 1 (Cerebral) & 12 & $722.3 \pm 435.3$ & 1045.9 & 721,8 & $159.0 / 1,302.9$ \\
\hline Group 2 (Hepatic) & 16 & $847.6 \pm 464.0$ & 971.9 & 786,4 & $317.6 / 2,352.6$ \\
\hline Total (G1+G2) & 28 & $793.9 \pm 456.2$ & 1004.4 & 786,4 & $159.0 / 2,352.6$ \\
\hline
\end{tabular}

${ }^{*} 75$ th Percentile Value.

G1, group 1; G2, group 2; SD, Standard deviation.

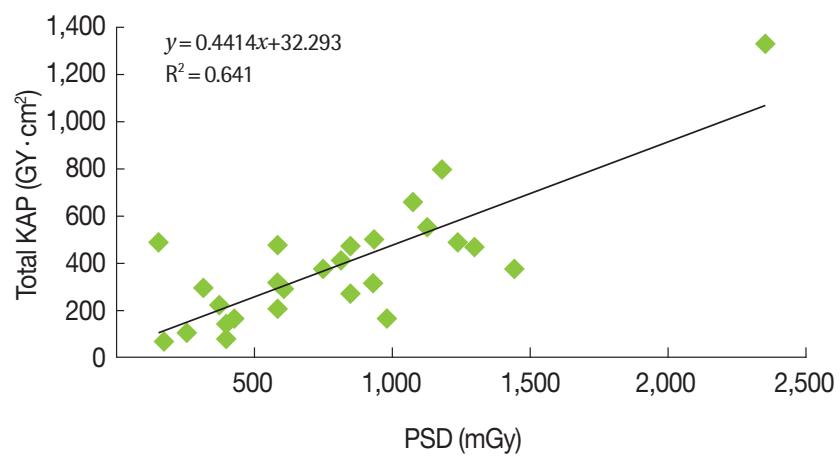

Fig. 3. Relationship between the kerma-Area Product (KAP) and Peak Skin Dose (PSD) at Therapeutic Procedures $(n=26)$.

Table 6 shows the maximum patient PSDs during the neuroembolization and chemoembolization procedures, which were determined using radiochromic film.

Figure 3 shows the correlation between the radiochromic film doses and the KAP values for 26 procedures from groups 


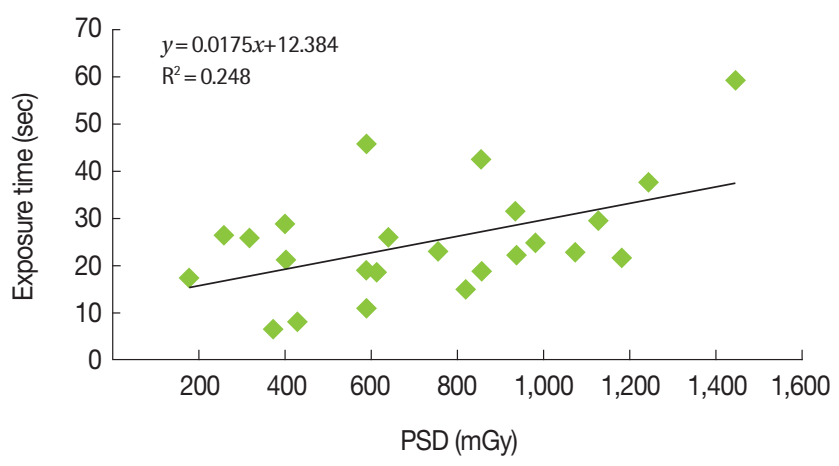

Fig. 4. Relationship between Exposure Time and Peak Skin Dose (PSD) at Therapeutic Procedures $(n=24)$.

1 and 2.

Figure 4 shows the relationship between the radiochromic film doses and total exposure times for acquisition mode and fluoroscopy mode during 24 procedures from groups 1 and 2 .

\section{Discussion}

Some authors have suggested evaluating doses in a large number of procedures, while other authors have recommended reference doses based on 10-50 cases [29, 30]. Wall [31] have suggested that developing a national reference level would require a minimum of 20 centres and 10 procedures from each centre (i.e., 200 total procedures).

Although reference levels are useful for dose optimisation and quality assessment, patients specific characteristics can limit the use of reference levels for examining procedure quality. This variability was observed in the present study, and is reflected in the highly variable KAP values from groups 1 and 2. Furthermore, given the asymmetrical data distribution, we reported the values for fluoroscopy, KAP fluoroscopy, KAP acquisition, accumulated KAP, and total images as the third quartile (median) values, which has also been used by other authors [31-33]. These results indicate that our average KAP values and total exposure times were similar to those from previous studies after accounting for the inherent uncertainty in these measurements $[29,34]$.

The radiochromic film has been strongly considered for measurement of patient skin dose during interventional procedures.

Gafchromic XR type-R radiochromic film energy response was investigated by researchers and the results showed that its energy dependence is minimal over the $75-125 \mathrm{kVp}$ range (9\% variation with $\pm 3 \%$ error) [35]. A study was conducted
Table 7. Maximum Doses on Patients Skin

\begin{tabular}{lccccc}
\hline \multirow{2}{*}{ Peak Skin Dose (Gy) } & \multicolumn{2}{c}{ Neuroembolization } & & \multicolumn{2}{c}{ Hepatic Chemoembolization } \\
\cline { 2 - 3 } \cline { 5 - 6 } & Variation & Mean & & Variation & Mean \\
\hline This study & $0.16-1.40$ & 0.72 & & $0.31-2.35$ & 0.85 \\
*TECDOC 1641- IAEA & $0.21-3.20$ & 1.90 & & $0.03-3.08$ & 1.80 \\
\hline
\end{tabular}

*A All India Institute of Medical Sciences Hospital, New Delhi, India. *B Santa Maria Hospital, Udine, Italy.

${ }^{*} \mathrm{C}$ Aichi Medical University Hospital, Aichi, Japan.

*D University of Malaya Medical Center, Kuala Lumpur, Malaysia.

*E King Chulalongkorn Memorial Hospital, Bangkok, Thailand.

${ }^{*} \mathrm{~F}$ University of Ankara, Faculty of Engineering, Department of Engineering Physics, Turkey.

to measure the skin dose during interventional neuroradiologic procedures with this kind of radiochromic film. The calibration was carried out at $80 \mathrm{kV}$ for the range of doses from 0 to $600 \mathrm{cGy}$. They considered the response to $80 \mathrm{kVp}$ is, on the average, $7 \%$ lower than the response to $120 \mathrm{kVp}$ x-rays. [36]. In a similar manner, considering the film stability, we have chosen a single calibration energy to convert film darkening to a map of skin dose carried out at $80 \mathrm{kVp}$ for the range of doses from 10 to $800 \mathrm{cGy}$.

Some researchers recognize the benefits of using film to estimate the patient s skin dose in interventional procedures even considering the challenges of using it, such as the cost and need for calibration. They concluded that the total uncertainty is $\pm 7.1 \%(\mathrm{k}=2)$, considering the uncertainties associated with the densitometer measurements and the calibration curve [37].

Radiochromic film are useful because they provide accurate PSD estimative at most exposed skin regions, and because KAP is not an ideal factor for predicting skin reactions $[34,36]$. Interestingly, the present study revealed PSD average values that were lower than IAEA data from six different countries (Table 7) [38].

J. C. Waite reported that "correlation between Entrance skin dose (ESD) and Dose área product (DAP) or fluoroscopy time could not be established for certain. The best correlation between DAP and ESD seemed to be for neurological examinations." At general interventional procedures, fluoroscopy time was found $\left(\mathrm{R}^{2}=0.75,16\right.$ patients), and correlation between DAP and ESD readings for neurological procedures using a $20 \mathrm{~cm}$ field of view was shown $\left(\mathrm{R}^{2}=0.87,10\right.$ patients) [39]. Other studies have indicated that KAP is negatively correlated with fluoroscopy time (Table 8) [40]. Nevertheless, D'Ercole et al. [37] have reported that there is often a "reasonable" correlation between PSD and KAP, which suggests that KAP values can be useful to predict whether the 
Table 8. Results from Researchers that Describe a Correlation $\left(R^{2}\right)$ among PSD, KAP and Exposure Time

\begin{tabular}{|c|c|c|c|c|}
\hline \multirow{2}{*}{ Correlation } & \multirow{2}{*}{$\begin{array}{c}\text { This study } \\
\text { Embolization }\left({ }^{*} \mathrm{G} 1+{ }^{*} \mathrm{G} 2\right)\end{array}$} & \multicolumn{2}{|c|}{ IAEA- TECDOC 1641} & \multirow{2}{*}{$\begin{array}{l}\text { D’ercole L. et al. } \\
\text { Neuroembolization }\end{array}$} \\
\hline & & Hepatic Chemoembolization & Neuroembolization & \\
\hline PSD/KAP & 0.70 & 0.64 & 0.53 & 0.77 \\
\hline PSD/Exp. Time & 0.24 & 0.14 & 0.42 & 0.61 \\
\hline KAP/Exp. Time & 0.09 & 0.11 & 0.68 & - \\
\hline
\end{tabular}

KAP, kerma-Area Product; PSD, Peak Skin Dose; G1, group 1; G2, group 2.

PSD will exceed the dose threshold for tissue reactions. Our results indicate that the correlation between exposure time and PSD was poor, although there was a good correlation between KAP and PSD.

The present study revealed that $66 \%$ of the procedures reached the notification level and approximately $23 \%$ reached the substantial radiation dose level. These data highlight the importance of dose monitoring at the equipment console, as well as subsequent analysis to identify patients with an elevated risk of tissue reactions. Furthermore, we identified three cases with a KAP that reached 500 $\mathrm{Gy} \cdot \mathrm{cm}^{2}$ and one case with a cumulative kerma of $>2 \mathrm{~Gy}$. Clinical staff has done a follow-up of patients, although no tissue reactions have been detected at this time.

The IAEA recommends that occupational dose monitoring should be performed at the chest level (inside and outside the lead apron), as well as at the eyes and hands [41].

We agree that it is appropriate to monitor occupational doses in different parts of the body, such as the hands, especially since the hands are closer to the patient than the trunk region of the interventional physician. Some authors recommend to monitoring hand dose on the little finger nearest to the x-ray tube. The question of whether the hands should be routinely monitored is not a consensus yet.

We decided not to use the Instadose ${ }^{\mathrm{TM}}$ dosimeter for physicians' hands monitoring considering that this type of electronic dosimeter could upset the procedure because of its size and risk in terms of infection control.

Clairand et al. [42] reported that active personal dosimeters were able to provide an appropriate response when lowenergy pulsed x-rays were used. The present study revealed that the various occupational doses were similar to the results from previous studies (Table 9). Nevertheless, occupational dose monitoring accuracy is affected by the dosimeter's position, the physician's position relative to the beam, and the radiation protocol. Vaño et al. [25] have recommend using a reference dosimeter on the $\mathrm{C}$-arm at approximately $95 \mathrm{~cm}$ from the isocentre, which may also be useful for esti-
Table 9. Equivalent Dose at Different Physician's Body Regions during Interventional Procedures

\begin{tabular}{lllll}
\hline \multicolumn{4}{l}{ Equivalent Dose (mSv) } \\
\cline { 2 - 5 } & \multicolumn{4}{c}{ Mean } \\
\cline { 2 - 4 } & & Left eye & Thorax & $\begin{array}{c}\text { Left } \\
\text { Ankle }\end{array}$ \\
\hline Neuro Interventional & This study & 0.11 & 0.05 & 0.28 \\
& Neuri et al. & 0.06 & 0.03 & 0.13 \\
& kemerink et al. (2002) & - & - & 0.38 \\
& Bor et al. (2008) & 0.11 & 0.03 & 0.04 \\
& Moritake et al. (2008) & 0.25 & 0.09 & - \\
\hline & & Left eye & \\
\cline { 2 - 4 } & & Median & $* 75$ th & \\
\hline Neuro Interventional & This study & 0.11 & 0.21 & \\
& Vaño et al. (2015) & 0.02 & 0.05 & \\
Interventional Radiology & Vaño et al. (2015) & 0.02 & 0.04 & \\
\hline
\end{tabular}

${ }^{\star} 75$ th percentile value.

mating the dose to the eye lens when personal dosimeters have not been regularly used. Based on their analysis, the dose to the unprotected eye lens is approximately $30 \%(6 \%$ for protected eyes) of the reference dose from the C-arm [25], and our Instadose ${ }^{\mathrm{TM}}$ data revealed a similar relationship.

The doses at the left ankle region were the highest, followed by the sphenoidal region (near the eyes) and chest region (over the apron). These results highlight the importance of routinely using a lead-lined curtain that is attached to the table.

Interestingly, the nursing team received doses that were approximately $30 \%$ of the dose received by the physicians. Based on the third quartile values, the occupational doses registered with Instadose ${ }^{\mathrm{TM}}$ dosimeter on the left orbit region (Group 2) indicated that the weekly dose limit for lens can be reached within around 15 procedures, considering that these professionals can receive an annual effective dose of $20 \mathrm{mSv}$, even if the ideal working conditions are maintained throughout the year.

The present study confirmed that PSD and KAP presented a realistic correlation, which indicates that the KAP value 
from the equipment console is relevant for monitoring PSD during interventional procedures. Furthermore, fluoroscopy time is the only routinely monitored parameter, and it is unable to alert physicians to doses that exceed the tissue reactions threshold.

Although the results from the present study agree with findings from previous multi-centre studies, it is important to collect data from a larger group of patients to develop a local reference dose for guiding radiation protection.

\section{References}

1. Bushong SC. Radiologic Science for Technologists. 7th ed. St Louis, MO: Mosby. 2001;364-616.

2. Sun Z, AbAziz A, Yusof AK. Radiation-induced noncancer risks in interventional cardiology: optimisation of procedures and staff and patient dose reduction. Biomed. Res. Int. 2013;2013: 962-976.

3. Freysz M, Mertz L, Lipsker D. Temporary localized alopecia following neuroradiological procedures: 18 cases. Ann. Dermatol. Venereol. 2014;141(1):15-22.

4. Rehani MM, Ortiz-Lopez P. Radiation effects in fluoroscopically guided cardiac interventions--keeping them under control. Int. J. Cardiol. 2006;109:147-151.

5. Bor D, Cekirge S, Türkay T, Turan O, Gülay M, Onal E, Cil B. Patient and staff doses in interventional neuroradiology. Radiat. Prot. Dosimetry. 2005;117:62-68.

6. Fletcher DW, Miller DL, Balter S, Taylor MA. Comparison of four techniques to estimate radiation dose to skin during angiographic and interventional radiology procedures. J. Vasc. Interv. Radiol. 2002;13:391-397.

7. D'Alessio D, Giliberti C, Soriani A, Carpanese L, Pizzi G, Vallati G, Strigari L. Dose evaluation for skin and organ in hepatocellular carcinoma during angiographic procedure. J. Exp. Clin. Cancer Res. 2013;25:32-81.

8. Ukisu R, Kushihashi T, Soh I. Skin injuries caused by fluoroscopically guided interventional procedures: case-based review and self-assessment module. AJR Am. J. Roentgenol. 2009;193(6 Suppl):59-69.

9. Vañó E, Arranz L, Sastre JM, Moro C, Ledo A, Gárate MT, Minguez I. Dosimetric and radiation protection considerations based on some cases of patient skin injuries in interventional cardiology. Br. J. Radiol. 1998;71:510-516.

10. Vaño E, Gonzalez L, Beneytez F, Moreno F. Lens injuries induced by occupational exposure in non-optimized interventional radiology laboratories. Br. J. Radiol. 1998;71:728-733.

11. Mooney RB, McKinstry CS, Kamel HA. Absorbed dose and deterministic effects to patients from interventional neuroradiology. Br. J. Radiol. 2000;73:745-751.
12. Theodorakou C, Horrocks JA. A study on radiation doses and irradiated areas in cerebral embolisation. Br. J. Radiol. 2003;76: 546-552.

13. Struelens L, Vanhavere F, Bosmans H, Van Loon R, Mol H. Skin dose measurements on patients for diagnostic and interventional neuroradiology: a multicentre study. Radiat. Prot. Dosimetry. 2005;114:143-146.

14. Verma S, Srinivas C, Thomas M. Radiation-induced temporary alopecia after embolization of cerebral aneurysm. Indian J. Dermatol. 2014;59(6):633.

15. Podlipnik S, Giavedoni P, San-Roman L, Ferrando J. Square alopecia: a new type of transient alopecia of the scalp following fluoroscopically endovascular embolization. Int. J. Trichology. 2013;5:201-203.

16. Huda W, Peters KR. Radiation-induced temporary epilation after a neuroradiologically guided embolization procedure. Radiology. 1994;193:642-644.

17. International Atomic Energy Agency. Diagnostic Radiology Physics: A Handbook for Teachers and Students. 2013;35-661.

18. International Commission on Radiological Protection. Avoidance of Radiation Injuries from Medical Interventional Procedures. 2000;30(2):7-67.

19. National Council on Radiation Protection and Measurements. Radiation Dose Management for Fluoroscopically-Guided Interventional Medical Procedures - NCRP Report No. 168;2010.

20. Mahesh M. NCRP 168: its significance to fluoroscopically guided interventional procedures. J. Am. Coll. Radiol. 2013;10:551-552.

21. United Nations Scientific Committee on the Effects Atomic Radiations. Source and effects of ionizing radiation. UNSCEAR 2008: report to the General Assembly with Scientific Annexes. 1. 2011;172-328.

22. Vaño E, Kleiman NJ, Duran A, Romano-Miller M, Rehani MM. Radiation-associated lens opacities in catheterization personnel: results of a survey and direct assessments. J. Vasc. Interv. Radiol. 2013;24:197-204.

23. Webinar: Radiation Protection of PationsUnit. Approaches to estimating radiation exposure to the lens of the eye during interventional procedures (4 May 2016, 3 pm CET). Available from: http://ns-files.iaea.org/video/rpop-webinar-4may.mp4 [in Spanish].

24. Roguin A, Goldstein J, Bar O. Brain tumours among interventional cardiologists: a cause for alarm? Report of four new cases from two cities and a review of the literature. EuroIntervention. 2012;7:1081-1086.

25. Vaño E, Fernandez JM, Sanchez RM, Dauer LT. Realistic approach to estimate lens doses and cataract radiation risk in cardiology when personal dosimeters have not been regularly used. Health Phys. 2013;105:330-339.

26. Jacob S, Boveda S, Bar O, Brézin A, Maccia C, Laurier D, Bernier MO. Interventional cardiologists and risk of radiation-induced 
cataract: results of a French multicenter observational study. Int. J. Cardiol. 2013;167:1843-1847.

27. Ciraj-Bjelac O, Beganovic A, Faj D, Ivanovic S, Videnovic I, Rehani M. Status of radiation protection in interventional cardiology in four East European countries. Radiat. Prot. Dosimetry. 2011;147:62-67.

28. Garzón WJ, Khoury H, Ovalle SAM, Medeiros RB. Performance of the Instadose ${ }^{\mathrm{TM}}$ Dosemeter for Interventional Radiology and Cardiology Application. Radiation Protection Dosimetry. 2019;183(4):522-528.

29. International Commission on Radiological Protection. Statement on tissue reactions and early and late effects of radiation in normal tissues and organs--threshold doses for tissue reactions in a radiation protection context. ICRP publication. 2012; 118:1-322.

30. International Atomic Energy Agency. Report of a consultation on justification of patient exposures in medical imaging. Radiat. Prot. Dosimetry. 2009;135:137-144.

31. Wall BF. Diagnostic reference levels--the way forward. Br. J. Radiol. 2001;74:785-788.

32. Mahesh M. Fluoroscopy: patient radiation exposure issues. Radiographics. 2001;21:1033-1045.

33. https://www.instadose.com, June 2017.

34. Rehani MM, Vaño E, Ciraj-Bjelac O, Kleiman NJ. Radiation and cataract. Radiat. Prot. Dosimetry. 2011;147:300-304.

35. Butson MJ, Cheung T, Peter KN. XR type-R radiochromic film X- ray energy response. Phys. Med. Biol. 2005;50:195-199.

36. D’Ercole L, Mantovani L, Thyrion FZ, Bocchiola M, Azzaretti A, Di Maria F, Saluzzo CM, Quaretti P, Rodolico G, Scagnelli P. A study on maximum skin dose in cerebral embolization procedures. AJNR. 2007;28:503-507.

37. McCabe BP, Speidel MA, Pike TL, Lysel MSV. Calibration of GafChromic XR-RV3 radiochromic film for skin dose measurement using standardized x-ray spectra and a commercial flatbed scanner. Med. Phys. 2011;38(4):1919-1930.

38. International Atomic Energy Agency. Patient Dose Optimization in fluoroscopically Guided Interventional Procedures: final report of a coordinated research project. IAEA Publication TECDOC. 2010;1641:17-106.

39. Waite JC, Fitzgerald M. An assessment of methods for monitoring entrance surface dose in fluoroscopically guided interventional procedures. Radiat. Prot. Dosimetry. 2001;94:89-92.

40. Schueler BA, Kallmes DF, Cloft HJ. 3D cerebral angiography: radiation dose comparison with digital subtraction angiography. AJNR. 2005;26:1898-1901.

41. Martin CJ. A review of radiology staff doses and dose monitoring requirements. Radiat Prot Dosimetry. 2009;136(3):140-157.

42. Clairand I, Struelens L, Bordy JM, Daures J, Debroas J, Denozières M, Donadille L, Gouriou J, Itié C, Vaz P. Intercomparison of active personal dosemeters in interventional radiology. Radiat. Prot. Dosimetry. 2008;129:340-345. 